\title{
UCP3 Regulates Single-Channel Activity of the Cardiac mCa1
}

\author{
Lukas J. Motloch ${ }^{1} \cdot$ Tina Gebing $^{1} \cdot \operatorname{Sara}_{\operatorname{Reda}^{1}} \cdot$ Astrid Schwaiger $^{1} \cdot$ \\ Martin Wolny ${ }^{1} \cdot$ Uta C. Hoppe $^{1}$
}

Received: 8 March 2016/Accepted: 15 June 2016/Published online: 1 July 2016

(C) The Author(s) 2016. This article is published with open access at Springerlink.com

\begin{abstract}
Mitochondrial $\mathrm{Ca}^{2+}$ uptake $\left(\mathrm{mCa}^{2+}\right.$ uptake) is thought to be mediated by the mitochondrial $\mathrm{Ca}^{2+}$ uniporter (MCU). UCP2 and UCP3 belong to a superfamily of mitochondrial ion transporters. Both proteins are expressed in the inner mitochondrial membrane of the heart. Recently, UCP2 was reported to modulate the function of the cardiac MCU related channel mCa1. However, the possible role of $\mathrm{UCP} 3$ in modulating cardiac $\mathrm{mCa}^{2+}$ uptake via the MCU remains inconclusive. To understand the role of UCP3, we analyzed cardiac mCa1 single-channel activity in mitoplast-attached single-channel recordings from isolated murine cardiac mitoplasts, from adult wildtype controls (WT), and from UCP3 knockout mice $\left(\mathrm{UCP}^{-1-}\right)$. Single-channel registrations in $\mathrm{UCP}^{-1-}$ confirmed a murine voltage-gated $\mathrm{Ca}^{2+}$ channel, i.e., mCa1, which was inhibited by Ru360. Compared to WT, mCa1 in $\mathrm{UCP}^{-1-}$ revealed similar single-channel characteristics. However, in $\mathrm{UCP}^{-/-}$the channel exhibited decreased single-channel activity, which was insensitive to adenosine triphosphate (ATP) inhibition. Our results suggest that beyond UCP2, UCP3 also exhibits regulatory effects on cardiac mCa1/MCU function. Furthermore, we speculate that UCP3 might modulate previously described inhibitory effects of ATP on mCa1/MCU activity as well.
\end{abstract}

Keywords UCP3 - Mitochondria - Calcium · Mitochondrial calcium uniporter $\cdot \mathrm{mCa} 1 \cdot \mathrm{ATP}$

Lukas J. Motloch

lukas.motloch@pmu.ac.at

1 Department of Internal Medicine II, Paracelsus Medical University, Muellner Hauptstr. 48, A-5020 Salzburg, Austria

\section{Introduction}

Mitochondrial $\mathrm{Ca}^{2+}$ handling is involved in several major cellular processes. It is known to regulate the rate of mitochondrial energy adenosine triphosphate (ATP) production (Jouaville et al. 1999; Territo et al. 2000), to control mitochondrial reactive oxygen species (ROS) generation (Kohlhaas et al.), and to supervise the initiation of cell death (Bernardi and Rasola 2007; Hoppe; O'Rourke 2007). Furthermore, it is supposed to modulate the profile of intracellular $\mathrm{Ca}^{2+}$ signaling (Kirichok et al. 2004; O'Rourke, 2007; Rizzuto et al. 1998).

Mitochondrial $\mathrm{Ca}^{2+}$ uptake $\left(\mathrm{mCa}^{2+}\right.$ uptake) is mainly mediated by the mitochondrial calcium uniporter (MCU) (Kirichok et al. 2004; Maack et al. 2006; Michels et al. 2009) which is highly sensitive to Ruthenium Red or to its more specific derivate Ruthenium360 (Ru360) (Brookes et al. 2008; Kirichok et al. 2004; Michels et al. 2009; Zazueta et al. 1999). The MCU was identified as a highly $\mathrm{Ca}^{2+}$-selective protein complex that consists of the poreforming mitochondrial $\mathrm{Ca}^{2+}$ uniporter protein (MCU) (Baughman et al. 2011; Chaudhuri et al. 2013; De Stefani et al. 2011), the essential MCU regulator (EMRE), and the mitochondrial calcium uptake 1 and 2 (MICU1/2) (Ahuja and Muallem 2014; Mallilankaraman et al. 2012; Perocchi et al. 2010; Plovanich et al. 2013). However, the function and regulatory mechanisms of MCU have not been fully understood yet.

In recent studies performed in mitoplasts isolated from HeLa cells, three mitochondrial $\mathrm{Ca}^{2+}$ channels have been identified (Bondarenko et al. 2013, 2014). Among them, the $i$-MCC was proven to display MCU- and MCU/EMREdependent activity, indicating it as an MCU-established current (Bondarenko et al. 2014). The single-channel characteristics of the channel correspond to the ruthenium 
sensitive cardiac current mCa1, which is supposed to underlie the MCU in the human and the murine heart (Bondarenko et al. 2013, 2014; Michels et al. 2009; Motloch et al. 2016).

Uncoupling proteins (UCPs) are found in the inner mitochondrial membrane and belong to a superfamily of mitochondrial ion transporters (Arsenijevic et al. 2000). $\mathrm{UCP} 2$ and UCP 3 are expressed in cardiac tissue (Alan et al. 2009). In the heart, these isoforms regulate cardiac ROS production and therefore reduce ischemia reperfusion injury (Chen et al. 2015; McLeod et al. 2005; Ozcan et al. 2013; Perrino et al. 2013; Safari et al. 2014; Teshima et al. 2003; Toime and Brand 2010). Recently, UCP2 was also shown to modulate cardioprotective effects of MCU inhibition (Motloch et al. 2015). However, the impact of both proteins on $\mathrm{mCa}^{2+}$ uptake remains still a matter of debate (Brookes et al. 2008; Trenker et al. 2007). In recent years, several studies have provided further evidence that indeed UCP2 and UCP3 are able to regulate mitochondrial $\mathrm{Ca}^{2+}$ handling (Waldeck-Weiermair et al. 2010a, b, 2011, 2013). In isolated mitoplasts, UCP2 was proven to modulate characteristics of mitochondrial $\mathrm{Ca}^{2+}$ channels (Bondarenko et al. 2015; Motloch et al. 2016) including the cardiac mCa1 (Motloch et al. 2016). Furthermore, in the heart, the protein was observed to mediate inhibitory effects on mCa1/MCU by ATP and to provoke changes of excitation-contraction coupling (Motloch et al. 2016).

However, if UCP3 may also modulate mCa1/MCU activity in the heart remains inconclusive. Therefore, to clarify this issue, we evaluated electrophysiological properties of the $\mathrm{mCa} 1$ in cardiac mitoplasts from $\mathrm{UCP}^{-1-}$ mice and wild-type controls (WT). Our data reveal that similar to findings obtained in $\mathrm{UCP} 2^{-1-}$ mice, UCP3 modulates the channel's activity in an ATP-dependent manner.

\section{Materials and Methods}

\section{Animals}

Animals were euthanized by cervical dislocation. For control experiments WT hearts were obtained from 12- to 16-week-old male C57BL/6 mice which were purchased from Charles River Laboratories, Research Models and Services, Germany. Male and female Ucp3 knockout mice $\left(\mathrm{UCP}^{-/-}{ }^{-}\right.$) (Gong et al. 2000) were crossed 10 times into the C57BL/6 background. Ucp3 ablation was confirmed in tails by PCR analysis of the genomic Ucp3 (Toime and Brand 2010). Male animals were sacrificed at age 12-16 weeks.

Animals were housed in the facilities of the Paracelsus Medical University, Salzburg. The implementation of the experiments conformed to the Guide for the Care and Use of Laboratory Animals published by the US National Institutes of Health (NIH publication No. 85-23, revised 1996).

\section{Preparation of Mitoplasts}

Isolated intact cardiac subsarcolemmal mitoplasts were prepared from isolated myocytes by differential centrifugation, as previously reported (Er et al. 2004; Kirichok et al. 2004; Michels et al. 2009; Motloch et al. 2016). Briefly, hearts were obtained from $\mathrm{WT}$ or $\mathrm{UCP}^{-1-}$ mice and single ventricular myocytes were isolated from murine hearts by enzymatic digestion, as previously described (Hoppe and Beuckelmann 1998; Lange et al. 2003; Michels et al. 2009; Motloch et al. 2016). Freshly isolated cardiomyocytes were used within 1-2 h. Myocytes were labeled with Mitotracker Green $1 \mu \mathrm{M}$ (Life Technologies, Carlsbad, CA, USA) to facilitate identification of intact mitoplasts after further subcellular purification (Er et al. 2004; Kirichok et al. 2004; Michels et al. 2009; Motloch et al. 2016). Mitochondria were stored at $4{ }^{\circ} \mathrm{C}$ for up to $24 \mathrm{~h}$ for patch-clamp experiments. Mitoplasts were prepared from intact mitochondria prior to patching or protein preparation by osmotic shock, as previously described $(\mathrm{Er}$ et al. 2004; Kirichok et al. 2004; Michels et al. 2009; Motloch et al. 2016).

\section{Single-Channel Recordings}

All experiments were performed in the mitoplast-attached configuration of the patch-clamp technique (at least 60 test pulses of $150-\mathrm{ms}$ duration at $1.67 \mathrm{~Hz}$, if not indicated otherwise; sampling frequency, $10 \mathrm{kHz}$; corner frequency, $2 \mathrm{kHz}$ ), as previously reported (Michels et al. 2009; Motloch et al. 2016). The bath solution contained $160 \mathrm{mM}$ $\mathrm{KCl}, 10 \mathrm{mM}$ HEPES, $1 \mathrm{mM}$ EDTA, 1 mM EGTA, pH 7.2 adjusted with $\mathrm{KOH}$. Pipettes were filled with a solution containing $105 \mathrm{mM} \mathrm{CaCl} 2,10 \mathrm{mM}$ HEPES, pH 7.2 adjusted with $\mathrm{Ca}(\mathrm{OH})_{2}$ (Er et al. 2004; Kirichok et al. 2004; Michels et al. 2009; Motloch et al. 2016). Specific drugs were added to the solutions to block the mitochondrial permeability transition pore $(10 \mu \mathrm{M}$ cyclosporine A, Sigma Aldrich, St. Louis, MO, USA), the mitochondrial ryanodine receptor $(10 \mu \mathrm{M}$ dantrolene, Sigma Aldrich, St. Louis, MO, USA), the inositol triphosphate receptor (10 $\mu \mathrm{M}$ xestospongin C, Sigma Aldrich, St. Louis, MO, USA), and the mitochondrial $\mathrm{Na}^{+}-\mathrm{Ca}^{2+}$ exchanger $(10 \mu \mathrm{M}$ CGP-37157, Calbiochem, San Diego, CA, USA) (Er et al. 2004; Kirichok et al. 2004; Michels et al. 2009; Motloch et al. 2016). Ru360 (10 $\mu$ M, Merck, Darmstadt, Germany) and ATP (1 mM, Sigma Aldrich, St. Louis, MO, USA) were added to the bath solution as indicated. Currents were recorded and digitized with an Axopatch 200B amplifier 
and Digidata 1200 interface (MDS Analytical Technologies, Toronto, Canada), as previously described (Gassanov et al. 2006; Lange et al. 2003; Michels et al. 2009; Motloch et al. 2016).

\section{Single-Channel Analysis}

Single-channel analysis was done using custom software only from one-channel patches, as previously reported $(\mathrm{Er}$ et al. 2004; Michels et al. 2009; Motloch et al. 2016). Briefly, linear leak and capacity currents were digitally subtracted using the average currents of nonactive sweeps. For detailed gating analysis, idealized currents were analyzed in $150 \mathrm{~ms}$ steps. Active sweeps were defined as those with at least one opening. The total open probability (Po, total; defined as the occupancy of the open state during the total pulse duration) was analyzed for at least $3 \mathrm{~s}$ pulse durations at $-100 \mathrm{mV}$ of 60 sweeps with $150 \mathrm{~ms}$ duration. Single-channel amplitudes were determined by direct measurements of fully resolved openings for conductance calculations or as the maximum of Gaussian fits to amplitude histograms (Michels et al. 2009; Motloch et al. 2016).

\section{Statistical Analysis}

$\mathrm{N}$ refers to the number of patch-experiments obtained in mitoplasts isolated from a minimum of three hearts. Pooled data are presented as mean \pm SEM. Comparisons between groups were performed with one-way ANOVA followed by post hoc Tukey test. Probability values of $P<0.05$ were regarded significant.

\section{Results}

\section{Characterization of mCa1 Single-Channel Activity in Subsarcolemmal, Cardiac Mitoplasts from $\mathrm{UCP3}^{-/-}$}

To clarify the role of UCP3 in cardiac $\mathrm{mCa}^{2+}$ uptake we analyzed single-channel currents in cardiac mitoplasts from $\mathrm{UCP}^{-1-}$ mice. By patch-clamping the inner membrane of subsarcolemmal mitoplasts prepared from isolated cardiomyocytes from $\mathrm{UCP}^{-/}{ }^{-}$, we verified the existence of murine mitochondrial mCa1 channels in $29 \%$ of total patches. Compared to WT $(21 \%) \mathrm{UCP}^{-1-}$ showed a trend towards an increase in the probability of occurrence (ratio of active to total patches), however, without reaching statistical significance $(P=0.20$, calculated by Chi Square test). In $\mathrm{UCP} 3^{-l-}$ we detected voltage-dependent singlechannel currents with a unitary conductance of $12.55 \pm 1.22 \mathrm{pS}$, three different amplitude sublevels with
$-1.16 \pm 0.02 \mathrm{pA}$ being the most common, and total open probability of $0.14 \pm 0.02 \%$ (Po, total at $-100 \mathrm{mV}$; Fig. 1; Table 1). Notably, neither channel's conductance nor the amplitude was different from WT (Table 1; Fig. 1d). However, compared to WT, UCP3 $3^{-1-}$ presented a significant reduction in total open probability and in mean open time, indicating $\mathrm{mCa} 1$ to be present but less active in $\mathrm{UCP}^{-1-}$ cardiac mitochondria (Fig. 1; Table 1).

\section{Characterization mCa1 Single-Channel Activity in Subsarcolemmal Cardiac Mitoplasts from $\mathrm{UCP3}^{-1-} \pm$ Ru360 and ATP}

mCa1/MCU activity is known to be inhibited by Ru360 (Kirichok et al. 2004; Michels et al. 2009; Motloch et al. 2016). Therefore, mCa1 sensitivity to Ru360 in UCP3 was evaluated (Fig. 2; Table 1). Consistent with data recently obtained in murine cardiac WT mitoplasts (Motloch et al. 2016), Ru360 significantly decreased the total open probability (Po, total: $0.04 \pm 0.01 \%, n=5, P<0.05$ ) without affecting further gating characteristics of the channel (Fig. 2; Table 1).

Since ATP was reported to inhibit cardiac mCa1 activity in a UCP2-dependent manner (Motloch et al. 2016), we speculated similar effects for UCP3. Thus, we performed additional experiments using ATP in $\mathrm{UCP}^{-1-}$. After application of ATP, no significant changes in total open probability were observed (Po, total $=0.10 \pm 0.03 \%$, $n=4, P=0.55$, Fig. 2; Table 1). In addition, no further single-channel characteristics were influenced by the nucleotide (Fig. 2; Table 1).

\section{Discussion}

The possible role of UCP2 and UCP3 in modulating $\mathrm{mCa}^{2+}$ uptake is a matter of debate (Brookes et al. 2008; Trenker et al. 2007). In a recent study, UCP2 was shown to regulate cardiac $\mathrm{mCa}^{2+}$ uptake by modulating $\mathrm{mCa} 1 / \mathrm{MCU}$ single-channel activity (Motloch et al. 2016). However, the role of UCP3 in regulating cardiac mitochondrial $\mathrm{Ca}^{2+}$ handling remains still inconclusive. Therefore, to define the role of UCP3, we performed single-channel recordings of subsarcolemmal mitoplasts prepared from isolated cardiomyocytes in $\mathrm{WT}$ and $\mathrm{UCP}^{-1-}$. In $\mathrm{UCP}^{-1-}$ mitoplasts we detected a murine cardiac $\mathrm{Ca}^{2+}$ channel which presented burst like open states, a mean amplitude of $-1.1-1.2 \mathrm{pA}$ at $-100 \mathrm{mV}$, and a conductance of 12-13 pS. These gating characteristics are specific for the murine and human mCa1 which correspond to the $i$-MCC as previously described in HeLa cells (Bondarenko et al. 2013, 2014; Michels et al. 2009; Motloch et al. 2016). Of note, the channel's activity characteristics have been 
A

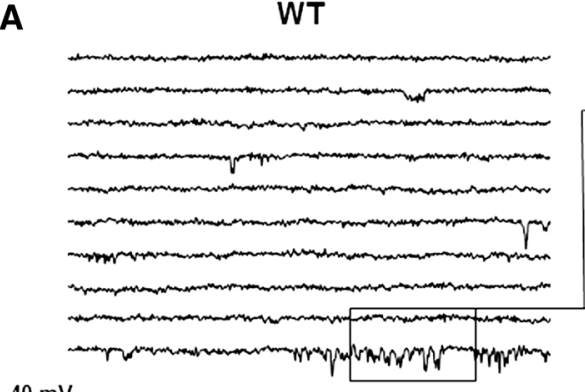

$.40 \mathrm{mV}$

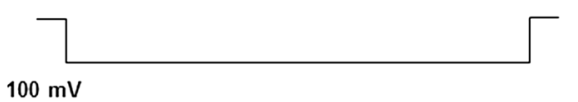

$\mathrm{UCP}^{-\mu}$

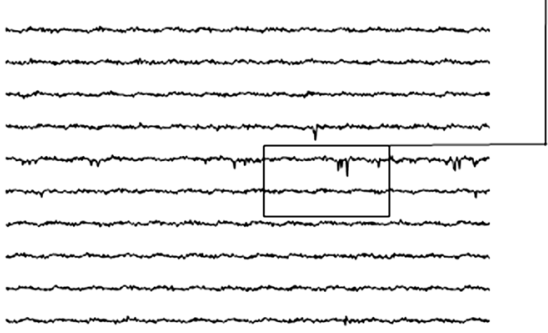

$2.5 \mathrm{pA}$

$50 \mathrm{~ms}$

Fig.1 a Examples of consecutive original traces of cardiac $\mathrm{mCa} 1$ in mitoplasts from $\mathrm{WT}$ and $\mathrm{UCP} 3^{-/-}$. b Amplitude histogram of $\mathrm{mCa} 1$ in mitoplasts from $\mathrm{UCP}^{-1-}$. $\mathrm{mCa} 1$ in $\mathrm{UCP}^{-1-}$ showed three amplitude levels with $-1.16 \mathrm{pA}$ being the most common observed amplitude $\left[\mathrm{I}_{\text {unitary }}:-1.16 \pm 0.05 \mathrm{pA}, n=21 ; \mu_{1}:-1.17 \mathrm{pA}(71 \%)\right.$, $\left.\mu_{2}:-1.80 \mathrm{pA}(28 \%), \mu_{3}:-3.72 \mathrm{pA}(1 \%)\right]$. c Total open probability

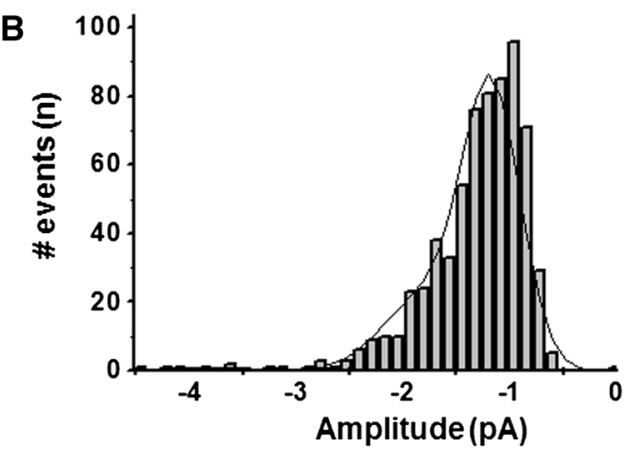

C
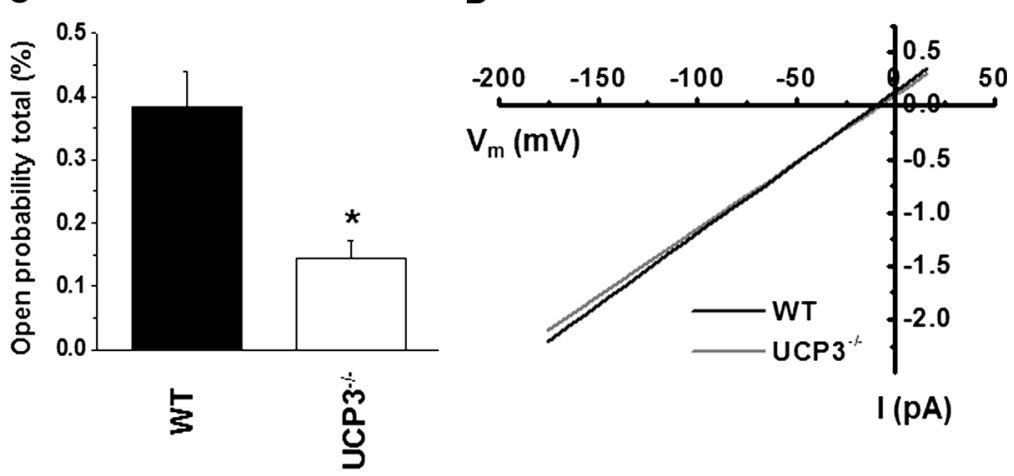

(Po, total) of $\mathrm{mCa} 1$ in $\mathrm{WT}$ and $\mathrm{UCP}^{-1-}$ : In comparison to WT, $\mathrm{mCa} 1, \mathrm{Po}$, total of $\mathrm{mCa} 1$ in $\mathrm{UCP}^{-1-}$ were significantly decreased $(* P<0.05)$. d Slope conductance of mCa1 in WT $(13.10 \pm 1.42 \mathrm{pS}$, $n=10)$ and of $\mathrm{mCa} 1$ in $\mathrm{UCP}^{-1-}(12.55 \pm 1.22 \mathrm{pS}, n=14)$ was not different

Table 1 Gating parameters of $\mathrm{mCa} 1$ in $\mathrm{WT}$ and $\mathrm{UCP}^{-1-}$

\begin{tabular}{|c|c|c|c|c|}
\hline & WT & $\mathrm{UCP}^{-} /^{-}$ & $\mathrm{UCP}^{-} /^{-}+\operatorname{Ru} 360(10 \mu \mathrm{M})$ & $\mathrm{UCP}^{-} /^{-}+\operatorname{ATP}(1 \mathrm{mM})$ \\
\hline Total open probability $(\%)$ & $0.38 \pm 0.04$ & $0.14 \pm 0.02 *$ & $0.04 \pm 0.01 *^{\#}$ & $0.10 \pm 0.03 *$ \\
\hline Mean open time (ms) & $0.36 \pm 0.02$ & $0.25 \pm 0.01 *$ & $0.24 \pm 0.05^{*}$ & $0.27 \pm 0.01$ \\
\hline Mean close time (ms) & $7.11 \pm 0.87$ & $10.64 \pm 0.75$ & $15.72 \pm 4.32 *$ & $15.66 \pm 5.07 *$ \\
\hline Mean first latency (ms) & $56.73 \pm 2.32$ & $59.52 \pm 2.60$ & $66.30 \pm 6.36$ & $58.81 \pm 5.25$ \\
\hline Amplitude/I $\mathrm{I}_{\text {unitary }}(\mathrm{pA})$ & $-1.20 \pm 0.03$ & $-1.16 \pm 0.02$ & $-1.14 \pm 0.03$ & $-1.16 \pm 0.03$ \\
\hline No. Experiments & 15 & 21 & 5 & 4 \\
\hline
\end{tabular}

Gating parameters of $\mathrm{mCa} 1$ in cardiac WT and $\mathrm{UCP}^{-1-}$ mitoplasts as well as in the presence of Ruthenium 360 (Ru360; $\left.10 \mu \mathrm{M}\right)$ or ATP $(1 \mathrm{mM})$ in $\mathrm{UCP}^{-/-}$. Holding potential $-40 \mathrm{mV}$, test potential $-100 \mathrm{mV}$

${ }^{*} P<0.05$ vs. WT; ${ }^{\#} P<0.05$ vs. $\mathrm{UCP}^{-1-}$ control

described to be indicative for the MCU-established current (Bondarenko et al. 2013, 2014; Michels et al. 2009; Motloch et al. 2016). Consistent with these observations, in our study $\mathrm{mCa} 1$ currents in $\mathrm{UCP} 3^{-/-}$were shown to be sensitive to Ru360 (Fig. 2; Table 1), which is known to block specifically the MCU (Kirichok et al. 2004; Zazueta et al.
1999). Therefore, despite earlier suggestions (Trenker et al. 2007), our results indicate, that UCP3 may not be essential for the MCU-established mitochondrial $\mathrm{Ca}^{2+}$ uptake. This conclusion is consistent with recent reports. The MCU was characterized as a highly $\mathrm{Ca}^{2+}$-selective protein complex that consists of the pore-forming mitochondrial $\mathrm{Ca}^{2+}$ 


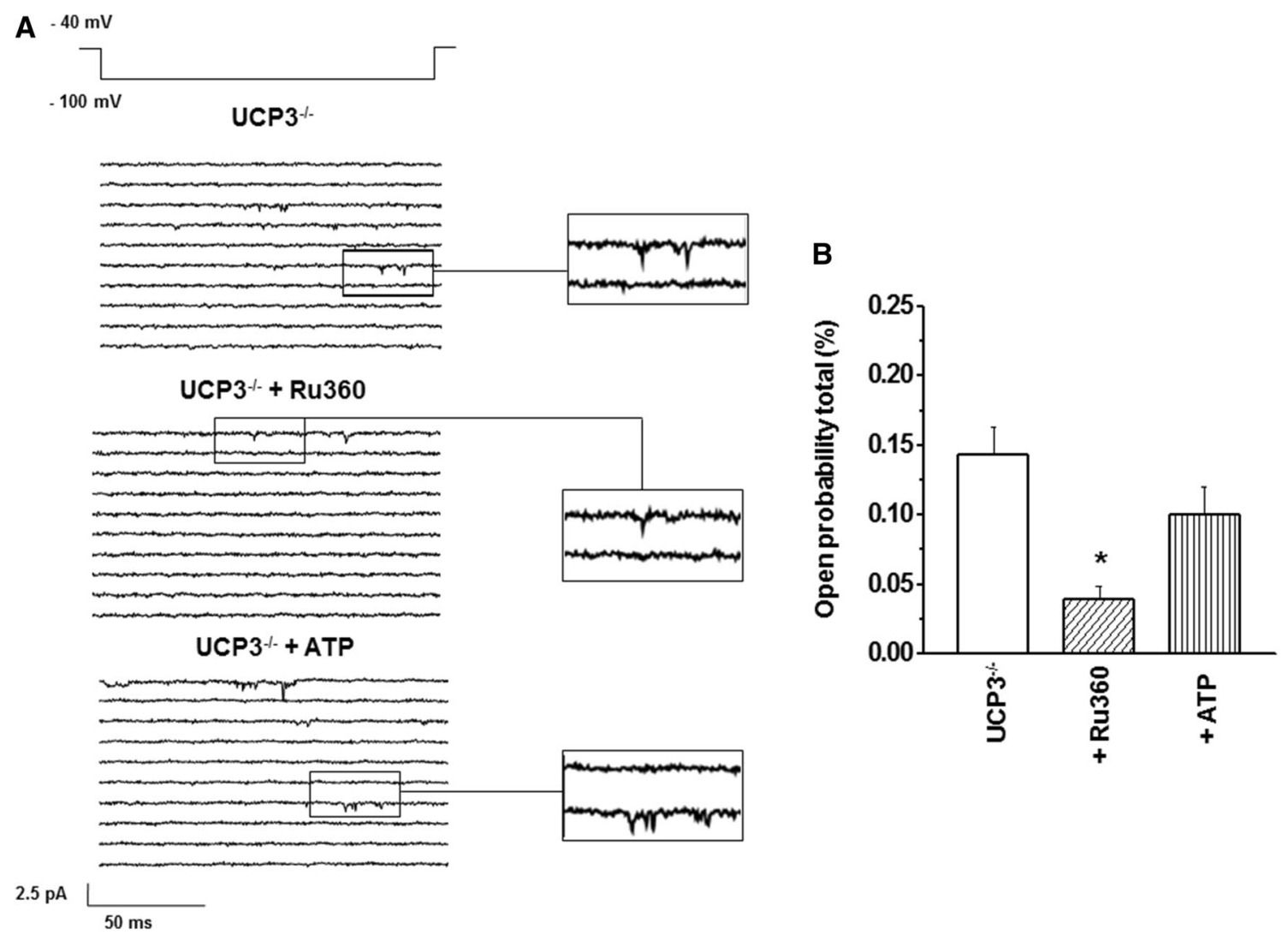

Fig.2 a Examples of consecutive original traces of cardiac $\mathrm{mCa} 1$ in mitoplast from $\mathrm{UCP}^{-1-}: \mathrm{mCa} 1$ in $\mathrm{UCP}^{-1-}$ control versus $\mathrm{mCa} 1$ in $\mathrm{UCP}^{-l-}+\mathrm{Ru} 360$ versus $\mathrm{mCa} 1$ in $\mathrm{UCP}^{-1-}+\mathrm{ATP}$. b In cardiac mitoplasts from $\mathrm{UCP}^{-1-} \operatorname{Ru} 360(10 \mu \mathrm{M}, n=5)$ significantly

uniporter protein (MCU) (Baughman et al. 2011; Chaudhuri et al. 2013; De Stefani et al. 2011), the essential MCU regulator (EMRE), and further regulatory proteins the mitochondrial calcium uptake 1 and 2 (MICU1/2) (Ahuja and Muallem 2014; Mallilankaraman et al. 2012; Perocchi et al. 2010; Plovanich et al. 2013).

However, in our study compared to WT, we detected a decreased single-channel activity in $\mathrm{UCP}^{-/-}$mitoplasts. A decrease in $\mathrm{mCa}^{2+}$ uptake after UCP3 depletion is consistent with previous reports obtained in intact and permeabilized HeLa as well as endothelial cells (Ahuja and Muallem 2014; Trenker et al. 2007; WaldeckWeiermair et al. 2010a, b, 2011, 2013). Our data extend these observations to the heart and furthermore reveal a physiological mechanism. We suggest that in the heart and probably also in other tissues, the protein influences $\mathrm{mCa}^{2+}$ uptake by modulating $\mathrm{mCa}$ /MCU single-channel activity. Therefore, our results might implicate that, as previously speculated for UCP2 (Motloch et al. 2016), UCP3 could operate cooperatively or sequentially for the modulation of transporting $\mathrm{Ca}^{2+}$ across the inner mitochondrial membrane as another part of the cardiac MCU complex system. decreased total open probability (Po, total) of mCa1 $(* P<0.05)$. ATP $(1 \mathrm{mM}, n=4)$ had no significant effect on mCa1 activity in $\mathrm{UCP}^{-l-}$

However, regulatory effects on further $\mathrm{mCa}^{2+}$ uptake mechanisms should be considered too. Of note, in respect to UCP2 function, a recent study in HeLa cells detected the protein to regulate the extra-large mitochondria calcium channel ( $x l$-MCC). This channel essentially contains MCU and EMRE. Notably, MCU was shown to have a much higher affinity to $x l$-MCC than to other MCU-dependent calcium currents including $i$-MCC (Bondarenko et al. 2015). An alternative explanation as how UCP3 might regulate $\mathrm{mCa}^{2+}$ uptake was reported by De Marchi and colleagues. The authors observed a modulation of mitochondrial $\mathrm{Ca}^{2+}$ by increased ATP and elevated SERCA activity leading to reduced depletion of the internal $\mathrm{Ca}^{2+}$ stores in intact HeLa cells under UCP3 depletion (De Marchi et al. 2011).

Altered UCP3 expression was demonstrated to influence cytosolic $\mathrm{Ca}^{2+}$ handling. In endothelial cells, distinct sites in the intermembrane loop 2 of the UCP3 protein were reported to modulate cytosolic and mitochondrial $\mathrm{Ca}^{2+}$ handling by sequestration of $\mathrm{Ca}^{2+}$ preferably released from the endoplasmatic reticulum (Waldeck-Weiermair et al. 2010a, b). In respect to cardiac tissue, changes in $\mathrm{mCa}^{2+}$ uptake in UCP2 knock down mice were shown to influence cytosolic $\mathrm{Ca}^{2+}$ 
handling by presenting a diminished trasnsarcolemmal $\mathrm{Ca}^{2+}$ influx in these animals (Motloch et al. 2016). Therefore, one might speculate that in the heart cytosolic $\mathrm{Ca}^{2+}$ handling might also be regulated by UCP3. However, these suggestions were not the matter of investigation in the present study and need to be addressed in further trials.

Previous studies also described inhibitory effects of adenine nucleotides especially of ATP on $\mathrm{mCa}^{2+}$ uptake (Litsky and Pfeiffer 1997) and on UCP activity, respectively (Echtay et al. 2001; Zackova et al. 2003). Indeed, recently ATP was shown to influence single-channel characteristics of $\mathrm{mCa} 1$ by reducing its total open probability without affecting further gating parameters (total open probability: WT $0.34 \pm 0.05$ vs. WT+ATP $0.06+0.01 ; P<0.05$; detailed gating characteristics are presented in Table 1 in Motloch et al. 2016). However, no effects were observed in UCP $2^{-/-}$ murine cardiac mitoplasts (total open probability: $\mathrm{UCP} 2^{-/-}$ $0.08 \pm 0.02$ vs. $\mathrm{UCP}^{-l-}+\mathrm{ATP} 0.06+0.01 ; P>0.05$; detailed gating characteristics are presented in Table 2 in Motloch et al. 2016). These observations were reassured in isolated cardiomyocytes indicating UCP2 to influence inhibitory effects of ATP on mCa1/MCU activity (Motloch et al. 2016). Therefore, we further decided to explore the impact of ATP in $\mathrm{UCP}^{-1-}$. In this study, with a number of four experiments, no significant effects of ATP on mCa1 activity were observed in $\mathrm{UCP}^{-1-}$ mice (total open probability: $\mathrm{UCP}^{-l-} 0.14 \pm 0.02$ vs. $\mathrm{UCP}^{-l-}+\mathrm{ATP} 0.10+0.03$; $P>0.05$; Table 1). This observation might support the notion that the inhibition of $\mathrm{mCa}^{2+}$ uptake by ATP might be mediated also via UCP3. However, regarding the limited number of experiments obtained by a challenging research technique in isolated cell organelles in this study, these conclusions should be applied with caution. Further studies, should confirm these speculations on the entire cell level.

Nevertheless, our results might be supported by a previous mentioned report from De Marchi and colleagues. Using histamine and boosting intracellular $\mathrm{Ca}^{2+}$ concentrations, the authors noted an increase in mitochondrial ATP concentrations in UCP3-depleted HeLa cells (De Marchi et al. 2011). They speculated, that a decline in uncoupling mechanisms and therefore a more efficient ATP synthase function might be responsible for their observations (De Marchi et al. 2011). Our data might provide an alternative explanation. MCU function was observed to be dependent on intracellular ATP concentrations (Motloch et al. 2016). In addition, the MCU was reported to be involved in the regulation of mitochondrial energy ATP production (Jouaville et al. 1999; Territo et al. 2000). Thus, one might speculate that under physiological conditions UCP3 (and probably also UCP2) seems to serve as a regulator of the respiratory chain via the modulation of
$\mathrm{mCa}^{2+}$ uptake indicating a physiological feedback mechanism in situations with high energy demands. However, in contrast to our data as well as in contrast to previous results obtained in permeabilized HeLa and endothelial cells (Trenker et al. 2007; Waldeck-Weiermair et al. 2010a, 2011) De Marchi and colleagues failed to record any differences in $\mathrm{mCa}^{2+}$ uptake in UCP3-depleted permeabilized cells (De Marchi et al. 2011). A possible explanation for their findings might be the usage of higher $\mathrm{Ca}^{2+}$ concentrations which could also activate further $\mathrm{mCa}^{2+}$ uptake mechanisms (Brustovetsky and Klingenberg 1996; Hoppe 2010; O’Rourke 2007).

How UCP3 and also as previously described UCP2 (Motloch et al. 2016) might potentially prevent the inhibitory effect of ATP and regulate mCa1 channel gating are not fully understood yet. Nevertheless, previous findings might contribute to some speculations. Both mitochondrial proteins are postulated to have a nucleotide-binding site which promotes inhibitory effects of ATP (Ricquier and Bouillaud 2000; Zackova et al. 2003). Therefore, ATP is described to decreased UCP-mediated proton leak. This mechanism could possibly promote local increases in proton concentration in the intermembrane space. Assuming that MCU and UCP2 or UCP3 might be colocalized in the inter mitochondrial membrane, one might speculate that the local change in proton concentrations would be able to influence the channel's activity. Of note, MCU function is known to be $\mathrm{pH}$ dependent (Reed and Bygrave 1975). However, further mechanisms should also be considered. By studying chimera constructs, Waldeck-Weiermair and colleagues elegantly demonstrated that distinct sites in the intermembrane loop 2 of UCP3 affect mitochondrial uptake of high and low calcium signals (Waldeck-Weiermair et al. 2010a). Of note, these specific sequences are not found in UCP1 (WaldeckWeiermair et al. 2010a). Their observations support the idea of a more complex regulatory mechanism. Therefore, one might further assume that specific sites of UCP2 or UCP3 could directly interact with or as a part of the MCU complex to differentially influence the open state of the channel in an ATP-dependent manner. Nevertheless, these speculations were not the matter of the current investigations and need be addressed in further trials.

\section{Conclusion}

In summary our study supports an essential role for UCP3 in modulating cardiac $\mathrm{mCa}^{2+}$ uptake via regulation of mCa1 single-channel activity. Furthermore, our data suggest that UCP3 might also modulate inhibitory effects of ATP on mCa1/MCU function. 
Funding This work was supported by grants from the Marga and Walter Boll-Stiftung.

\section{Compliance with Ethical Standards}

Conflict of interest No conflicts of interest, financial or otherwise are declared by the authors.

Ethical approval All applicable international, national, and/or institutional guidelines for the care and use of animals were followed. This article does not contain any studies with human participants performed by any of the authors.

Open Access This article is distributed under the terms of the Creative Commons Attribution 4.0 International License (http://crea tivecommons.org/licenses/by/4.0/), which permits unrestricted use, distribution, and reproduction in any medium, provided you give appropriate credit to the original author(s) and the source, provide a link to the Creative Commons license, and indicate if changes were made.

\section{References}

Ahuja M, Muallem S (2014) The gatekeepers of mitochondrial calcium influx: MICU1 and MICU2. EMBO Rep 15:205-206

Alan L, Smolkova K, Kronusova E, Santorova J, Jezek P (2009) Absolute levels of transcripts for mitochondrial uncoupling proteins $\mathrm{UCP} 2, \mathrm{UCP} 3, \mathrm{UCP} 4$, and UCP5 show different patterns in rat and mice tissues. J Bioenerg Biomembr 41:71-78

Arsenijevic D, Onuma H, Pecqueur C, Raimbault S, Manning BS, Miroux B, Couplan E, Alves-Guerra MC, Goubern M, Surwit R, Bouillaud F, Richard D, Collins S, Ricquier D (2000) Disruption of the uncoupling protein-2 gene in mice reveals a role in immunity and reactive oxygen species production. Nat Genet 26:435-439

Baughman JM, Perocchi F, Girgis HS, Plovanich M, Belcher-Timme CA, Sancak Y, Bao XR, Strittmatter L, Goldberger O, Bogorad RL, Koteliansky V, Mootha VK (2011) Integrative genomics identifies MCU as an essential component of the mitochondrial calcium uniporter. Nature 476:341-345

Bernardi P, Rasola A (2007) Calcium and cell death: the mitochondrial connection. Subcell Biochem 45:481-506

Bondarenko AI, Jean-Quartier C, Malli R, Graier WF (2013) Characterization of distinct single-channel properties of $\mathrm{Ca}(2)(+)$ inward currents in mitochondria. Pflugers Arch 465:997-1010

Bondarenko AI, Jean-Quartier C, Parichatikanond W, Alam MR, Waldeck-Weiermair M, Malli R, Graier WF (2014) Mitochondrial $\mathrm{Ca}(2+)$ uniporter (MCU)-dependent and MCU-independent $\mathrm{Ca}(2+)$ channels coexist in the inner mitochondrial membrane. Pflugers Arch 466:1411-1420

Bondarenko AI, Parichatikanond W, Madreiter CT, Rost R, WaldeckWeiermair M, Malli R, Graier WF (2015) UCP2 modulates single-channel properties of a MCU-dependent $\mathrm{Ca}$ inward current in mitochondria. Pflugers Arch 467(12):2509-2518

Brookes PS, Parker N, Buckingham JA, Vidal-Puig A, Halestrap AP, Gunter TE, Nicholls DG, Bernardi P, Lemasters JJ, Brand MD (2008) UCPs-unlikely calcium porters. Nat Cell Biol 10:1235-1237

Brustovetsky N, Klingenberg M (1996) Mitochondrial ADP/ATP carrier can be reversibly converted into a large channel by $\mathrm{Ca} 2+$. Biochem 35:8483-8488
Chaudhuri D, Sancak Y, Mootha VK, Clapham DE (2013) MCU encodes the pore conducting mitochondrial calcium currents. Elife 2:e00704

Chen Y, Liu J, Zheng Y, Wang J, Wang Z, Gu S, Tan J, Jing Q, Yang $\mathrm{H}$ (2015) Uncoupling protein 3 mediates $\mathrm{H}(2) \mathrm{O}(2)$ preconditioning-afforded cardioprotection through the inhibition of MPTP opening. Cardiovasc Res 105:192-202

De Marchi U, Castelbou C, Demaurex N (2011) Uncoupling protein 3 (UCP3) modulates the activity of Sarco/endoplasmic reticulum Ca2+-ATPase (SERCA) by decreasing mitochondrial ATP production. J Biol Chem 286:32533-32541

De Stefani D, Raffaello A, Teardo E, Szabo I, Rizzuto R (2011) A forty-kilodalton protein of the inner membrane is the mitochondrial calcium uniporter. Nature 476:336-340

Echtay KS, Winkler E, Frischmuth K, Klingenberg M (2001) Uncoupling proteins 2 and 3 are highly active $\mathrm{H}(+)$ transporters and highly nucleotide sensitive when activated by coenzyme Q (ubiquinone). Proc Natl Acad Sci USA 98:1416-1421

Er F, Michels G, Gassanov N, Rivero F, Hoppe UC (2004) Testosterone induces cytoprotection by activating ATP-sensitive $\mathrm{K}+$ channels in the cardiac mitochondrial inner membrane. Circulation 110:3100-3107

Gassanov N, Brandt MC, Michels G, Lindner M, Er F, Hoppe UC (2006) Angiotensin II-induced changes of calcium sparks and ionic currents in human atrial myocytes: potential role for early remodeling in atrial fibrillation. Cell Calcium 39:175-186

Gong DW, Monemdjou S, Gavrilova O, Leon LR, Marcus-Samuels B, Chou CJ, Everett C, Kozak LP, Li C, Deng C, Harper ME, Reitman ML (2000) Lack of obesity and normal response to fasting and thyroid hormone in mice lacking uncoupling protein3. J Biol Chem 275:16251-16257

Hoppe UC (2010) Mitochondrial calcium channels. FEBS Lett 584:1975-1981

Hoppe UC, Beuckelmann DJ (1998) Characterization of the hyperpolarization-activated inward current in isolated human atrial myocytes. Cardiovasc Res 38:788-801

Jouaville LS, Pinton P, Bastianutto C, Rutter GA, Rizzuto R (1999) Regulation of mitochondrial ATP synthesis by calcium: evidence for a long-term metabolic priming. Proc Natl Acad Sci USA 96:13807-13812

Kirichok Y, Krapivinsky G, Clapham DE (2004) The mitochondrial calcium uniporter is a highly selective ion channel. Nature 427:360-364

Kohlhaas M, Liu T, Knopp A, Zeller T, Ong MF, Bohm M, O'Rourke B, Maack C (2010) Elevated cytosolic $\mathrm{Na}$ +increases mitochondrial formation of reactive oxygen species in failing cardiac myocytes. Circulation 121:1606-1613

Lange PS, Er F, Gassanov N, Hoppe UC (2003) Andersen mutations of KCNJ2 suppress the native inward rectifier current IK1 in a dominant-negative fashion. Cardiovasc Res 59:321-327

Litsky ML, Pfeiffer DR (1997) Regulation of the mitochondrial $\mathrm{Ca} 2^{+}$uniporter by external adenine nucleotides: the uniporter behaves like a gated channel which is regulated by nucleotides and divalent cations. Biochem 36:7071-7080

Maack C, Cortassa S, Aon MA, Ganesan AN, Liu T, O'Rourke B (2006) Elevated cytosolic $\mathrm{Na}^{+}$decreases mitochondrial Ca2 ${ }^{+}$uptake during excitation-contraction coupling and impairs energetic adaptation in cardiac myocytes. Circ Res 99:172-182

Mallilankaraman K, Doonan P, Cardenas C, Chandramoorthy HC, Muller M, Miller R, Hoffman NE, Gandhirajan RK, Molgo J, Birnbaum MJ, Rothberg BS, Mak DO, Foskett JK, Madesh M (2012) MICU1 is an essential gatekeeper for MCU-mediated mitochondrial $\mathrm{Ca}(2+)$ uptake that regulates cell survival. Cell 151:630-644 
McLeod CJ, Aziz A, Hoyt RF Jr, McCoy JP Jr, Sack MN (2005) Uncoupling proteins 2 and 3 function in concert to augment tolerance to cardiac ischemia. J Biol Chem 280:33470-33476

Michels G, Khan IF, Endres-Becker J, Rottlaender D, Herzig S, Ruhparwar A, Wahlers T, Hoppe UC (2009) Regulation of the human cardiac mitochondrial $\mathrm{Ca} 2^{+}$uptake by 2 different voltagegated $\mathrm{Ca} 2{ }^{+}$channels. Circulation 119:2435-2443

Motloch LJ, Reda S, Wolny M, Hoppe UC (2015) UCP2 modulates cardioprotective effects of Ru360 in isolated cardiomyocytes during ischemia. Pharmaceuticals (Basel) 8:474-482

Motloch LJ, Larbig R, Gebing T, Reda S, Schwaiger A, Leitner J, Wolny M, Eckardt L, Hoppe UC (2016) By Regulating Mitochondrial $\mathrm{Ca}_{2}{ }^{+}$-Uptake UCP2 Modulates Intracellular Ca2. PLoS One 11:e0148359

O'Rourke B (2007) Mitochondrial ion channels. Annu Rev Physiol 69:19-49

Ozcan C, Palmeri M, Horvath TL, Russell KS, Russell RR 3rd (2013) Role of uncoupling protein 3 in ischemia-reperfusion injury, arrhythmias, and preconditioning. Am J Physiol Heart Circ Physiol 304:H1192-H1200

Perocchi F, Gohil VM, Girgis HS, Bao XR, McCombs JE, Palmer AE, Mootha VK (2010) MICU1 encodes a mitochondrial EF hand protein required for $\mathrm{Ca}\left(2^{+}\right)$uptake. Nature 467:291-296

Perrino C, Schiattarella GG, Sannino A, Pironti G, Petretta MP, Cannavo A, Gargiulo G, Ilardi F, Magliulo F, Franzone A, Carotenuto G, Serino F, Altobelli GG, Cimini V, Cuocolo A, Lombardi A, Goglia F, Indolfi C, Trimarco B, Esposito G (2013) Genetic deletion of uncoupling protein 3 exaggerates apoptotic cell death in the ischemic heart leading to heart failure. J Am Heart Assoc 2:e00086

Plovanich M, Bogorad RL, Sancak Y, Kamer KJ, Strittmatter L, Li AA, Girgis HS, Kuchimanchi S, De Groot J, Speciner L, Taneja N, Oshea J, Koteliansky V, Mootha VK (2013) MICU2, a paralog of MICU1, resides within the mitochondrial uniporter complex to regulate calcium handling. PLoS One 8:e55785

Reed KC, Bygrave FL (1975) A kinetic study of mitochondrial calcium transport. Eur J Biochem 55:497-504

Ricquier D, Bouillaud F (2000) The uncoupling protein homologues: UCP1, UCP2, UCP3. StUCP and AtUCP. Biochem J 345(Pt 2):161-179

Rizzuto R, Pinton P, Carrington W, Fay FS, Fogarty KE, Lifshitz LM, Tuft RA, Pozzan T (1998) Close contacts with the endoplasmic reticulum as determinants of mitochondrial $\mathrm{Ca}_{2}{ }^{+}$responses. Science 280:1763-1766

Safari F, Bayat G, Shekarforoush S, Hekmatimoghaddam S, Anvari Z, Moghadam MF, Hajizadeh S (2014) Expressional profile of cardiac uncoupling protein-2 following myocardial ischemia reperfusion in losartan- and ramiprilat-treated rats. J Renin Angiotensin Aldosterone Syst 15:209-217

Territo PR, Mootha VK, French SA, Balaban RS (2000) $\mathrm{Ca}\left(2^{+}\right)$ activation of heart mitochondrial oxidative phosphorylation: role of the $\mathrm{F}(0) / \mathrm{F}(1)$-ATPase. Am J Physiol Cell Physiol 278:C423C435

Teshima Y, Akao M, Jones SP, Marban E (2003) Uncoupling protein2 overexpression inhibits mitochondrial death pathway in cardiomyocytes. Circ Res 93:192-200

Toime LJ, Brand MD (2010) Uncoupling protein-3 lowers reactive oxygen species production in isolated mitochondria. Free Radic Biol Med 49:606-611

Trenker M, Malli R, Fertschai I, Levak-Frank S, Graier WF (2007) Uncoupling proteins 2 and 3 are fundamental for mitochondrial $\mathrm{Ca} 2+$ uniport. Nat Cell Biol 9:445-452

Waldeck-Weiermair M, Duan X, Naghdi S, Khan MJ, Trenker M, Malli R, Graier WF (2010a) Uncoupling protein 3 adjusts mitochondrial $\mathrm{Ca}\left(2^{+}\right)$uptake to high and low $\mathrm{Ca}\left(2^{+}\right)$signals. Cell Calcium 48:288-301

Waldeck-Weiermair M, Malli R, Naghdi S, Trenker M, Kahn MJ, Graier WF (2010b) The contribution of UCP2 and UCP3 to mitochondrial $\mathrm{Ca}\left(2^{+}\right)$uptake is differentially determined by the source of supplied $\mathrm{Ca}\left(2^{+}\right)$. Cell Calcium 47:433-440

Waldeck-Weiermair M, Jean-Quartier C, Rost R, Khan MJ, Vishnu N, Bondarenko AI, Imamura H, Malli R, Graier WF (2011) Leucine zipper EF hand-containing transmembrane protein 1 (Letm1) and uncoupling proteins 2 and 3 (UCP2/3) contribute to two distinct mitochondrial $\mathrm{Ca}^{+}{ }^{+}$uptake pathways. J Biol Chem 286:28444-28455

Waldeck-Weiermair M, Deak AT, Groschner LN, Alam MR, JeanQuartier C, Malli R, Graier WF (2013) Molecularly distinct routes of mitochondrial $\mathrm{Ca}_{2}^{+}$uptake are activated depending on the activity of the sarco/endoplasmic reticulum $\mathrm{Ca}_{2}{ }^{+}$ATPase (SERCA). J Biol Chem 288:15367-15379

Zackova M, Skobisova E, Urbankova E, Jezek P (2003) Activating omega-6 polyunsaturated fatty acids and inhibitory purine nucleotides are high affinity ligands for novel mitochondrial uncoupling proteins UCP2 and UCP3. J Biol Chem 278:20761-20769

Zazueta C, Sosa-Torres ME, Correa F, Garza-Ortiz A (1999) Inhibitory properties of ruthenium amine complexes on mitochondrial calcium uptake. J Bioenerg Biomembr 31:551-557 